\title{
Extracellular Vesicles from Human Urine-Derived Stem Cells Ameliorate Particulate Polyethylene-Induced Osteolysis
}

\author{
Hui $\mathrm{Li}^{1,2, *}$ \\ Xiao-Lei Fan ${ }^{1,2, *}$ \\ Yi-Nan Wang ${ }^{1,2}$ \\ Wei Lu ${ }^{1,2}$ \\ Haoyi Wang ${ }^{1,2}$ \\ Runzhi Liao ${ }^{1,2}$ \\ Min Zeng ${ }^{\mathrm{I}, 2}$ \\ Jun-Xiao Yang ${ }^{1,2}$ \\ Yihe $\mathrm{Hu}^{\mathrm{l}, 2}$ \\ Jie Xie (D) ${ }^{1,2}$ \\ 'Department of Orthopedics, Xiangya \\ Hospital, Central South University, \\ Changsha, Hunan, People's Republic of \\ China; ${ }^{2}$ Hunan Engineering Research \\ Center of Biomedical Metal and Ceramic \\ Implants, Xiangya Hospital, Central South \\ University, Changsha, Hunan, People's \\ Republic of China
}

*These authors contributed equally to this work

\begin{abstract}
Purpose: Wear debris particle-induced periprosthetic osteolysis is a severe complication of total joint replacement that results in aseptic loosening and subsequent arthroplasty failure. No effective therapeutic agents or drugs have been approved to prevent or treat osteolysis; thus, revision surgery is often needed. Extracellular vesicles (EVs) are vital nanosized regulators of intercellular communication that can be directly applied to promote tissue repair and regeneration. In this study, we assessed the therapeutic potential of EVs from human urine-derived stem cells (USCs) (USC-EVs) in preventing ultrahigh-molecularweight polyethylene (UHMWPE) particle-induced osteolysis.
\end{abstract}

Methods: USCs were characterized by measuring induced multipotent differentiation and flow cytometry. USC-EVs were isolated and characterized using transmission electron microscopy (TEM), dynamic light scattering (DLS) and Western blotting. RAW264.7 cells and bone marrow mesenchymal stem cells (BMSCs) were cultured with USC-EVs to verify osteoclast differentiation and osteoblast formation, respectively, in vitro. The effects of USCEVs were investigated on a UHMWPE particle-induced murine calvarial osteolysis model by assessing bone mass, the inflammatory reaction, and osteoblast and osteoclast formation.

Results: USCs differentiated into osteogenic, adipogenic and chondrogenic cells in vitro and were positive for CD44, CD73, CD29 and CD90 but negative for CD34 and CD45. USCEVs exhibited a cup-like morphology with a double-layered membrane structure and were positive for CD63 and TSG101 and negative for calnexin. In vitro, USC-EVs promoted the osteogenic differentiation of BMSCs and reduced proinflammatory factor production and osteoclastic activity in RAW264.7 cells. In vivo, local injection of USC-EVs around the central sites of the calvaria decreased inflammatory cytokine generation and osteolysis compared with the control groups and significantly increased bone formation.

Conclusion: Based on our findings, USC-EVs prevent UHMWPE particle-induced osteolysis by decreasing inflammation, suppressing bone resorption and promoting bone formation.

Keywords: extracellular vesicles, urine-derived stem cells, UHMWPE, wear particleinduced osteolysis, anti-inflammatory

\section{Introduction}

Total joint arthroplasty (TJA) is a highly effective method to treat severe joint diseases, such as complex fractures, osteoarthritis, rheumatoid arthritis and osteonecrosis. TJA effectively alleviates pain and improves the quality of life of patients with joint disease. $^{1,2}$ Every year, approximately 1.5 million joint replacement operations are performed worldwide, and the demand for these surgeries is increasing. ${ }^{3}$ Despite
Department of Orthopedics, Xiangya Hospital, Central South University, \#87

Xiangya Road, Changsha, Hunan, 410008 ,

People's Republic of China

Tel +86-73I-89753006;

$+86-731-89753706$

Email dr_xiejie@l63.com;

csuhuyihe@I63.com 
continuing innovation in biomaterial technology and a new understanding of biomechanics, an absolute decrease in revision rates has not been realized in recent years. ${ }^{4}$ Despite the excellent outcomes of TJA, aseptic loosening, which occurs in approximately $75 \%$ of all cases, remains the principal cause of arthroplasty component failure requiring surgical revision, which has a serious impact on both the patient and the entire healthcare system. ${ }^{5}$ The pathophysiology of aseptic loosening is still being explored, but accumulating evidence indicates that inflammatory responses to implant wear debris are the main and initial cause of aseptic loosening. ${ }^{6}$ The generation of bioactive implant wear debris, such as UHMWPE, metal and polymethylmethacrylate (PMMA), is involved in the initiation and development of periprosthetic osteolysis. In addition, periprosthetic osteolysis resulting from the generation of UHMWPE particles in prosthetic components is considered one of the most important complications following TJA. ${ }^{7}$ Periprosthetic osteolysis starts with the production of wear debris particles, which induce the secretion of various inflammatory cytokines, such as IL-6, IL-1 $\beta$, and TNF- $\alpha$, from macrophages and T lymphocytes. ${ }^{8,9}$ In turn, these proinflammatory cytokines simultaneously stimulate osteoclast precursor cells and target other cells, mainly osteoblasts and bone marrow mesenchymal stem cells (BMSCs), to promote the secretion of receptor activator of nuclear factor-KB ligand (RANKL), a critical regulator of osteoclastogenesis. The binding of RANKL to its receptor RANK subsequently initiates intracellular signaling pathways to accelerate osteoclast differentiation. Therefore, substantial osteoclast activation appears between bone and periprosthetic sites, eventually resulting in extensive bone loss. ${ }^{8,9}$ Inflammatory responses, bone resorption, and foreign body granuloma formation are the fundamental factors that lead to osteolysis. ${ }^{10}$ Because osteoclasts play a vital role in the development of osteolysis, bioactive substances that specifically target osteoclasts to inhibit their formation and activation are potential agents for the prevention or treatment of wear particle-induced osteolysis. Currently, no related therapeutic drugs have been approved to prevent or treat periprosthetic osteolysis, and only revision surgery is available to treat aseptic loosening.

Stem cell biology is a promising field that has achieved remarkable progress in damage repair. Increasing evidence from animal models has shown that transplanted stem cells colonize injury sites, and a single-dose injection of stem cells is sufficient to alleviate disease symptoms; furthermore, the long-term therapeutic efficacy of stem cells is maintained, ${ }^{11,12}$ indicating that their paracrine activity may be the key mechanism responsible for their beneficial effects. Stem cells secrete extracellular vesicles (EVs, 100-1,000 nm in diameter) of different sizes, such as exosomes, microvesicles, and microparticles. ${ }^{13}$ In recent years, exosomes, which are $30-150 \mathrm{~nm}$ in diameter, originate from cell multivesicular bodies (MVBs) and are released to the extracellular environment via cell membrane fusion, have attracted increasing interest from researchers. ${ }^{13,14}$ Exosomes have an external lipid bilayer that contains transmembrane proteins and envelopes endocellular proteins and RNA. Exosomes target adjacent cells or are transported in the blood to distant sites, where they stimulate signal transduction in recipient cells. ${ }^{13,14}$ Based on accumulating evidence, direct application of secreted vesicles promotes osteogenesis, and these vesicles avoid many of the disadvantages associated with stem cell therapy, ${ }^{11,15,16}$ such as chromosome variation, potential immunological rejection, and emboli formation. Nevertheless, the desire to liberally apply stem cells is restricted, mainly due to the limited sources of these cells, genetic and epigenetic variations, and the invasive and painful isolation method. ${ }^{17-19}$ Hence, the identification of a new stem cell source from which to easily and noninvasively obtain large amounts of EVs for bone remodeling and regeneration is an urgent need.

Recently, a special type of stem cell that can be easily harvested from human urine samples has been reported, ${ }^{17,20-23}$ namely, human urine-derived stem cells (USCs). USCs exhibit the characteristics of all stem cells, such as multipotent differentiation, cell surface marker expression, specific cell growth patterns and easily induced pluripotency. ${ }^{21}$ Overall, the most important reason to utilize USCs is that these stem cells can be noninvasively and easily obtained. Chen et al used human USCs to isolate EVs (USC-EVs) and verified that USC-EVs significantly promoted osteogenesis and inhibited osteoclastogenesis in osteoporotic mice. ${ }^{17}$ Additionally, a single administration of USCs was reported to promote bone tissue regeneration. Guan et al showed that a $\beta$-tricalcium phosphate scaffold seeded with USCs promotes bone healing in rats with femoral defects. ${ }^{24}$ Considering that EVs play an important role in intercellular interactions during cellular activity, ${ }^{13,14}$ an important and interesting approach would be to verify whether USC-EVs prevent or inhibit osteolysis to develop a new preventive strategy that inhibits UHMWPE particleinduced osteolysis.

In this study, we explored the effects of USC-EVs on osteogenic activity and osteoclast formation by coculturing EVs with mouse BMSCs and RAW264.7 cells. In vivo, we 
further observed that USC-EVs alleviated osteolysis in a murine osteolysis model. Our data indicated that USCEVs prevent osteoclast differentiation and promote bone regeneration by inhibiting the inflammatory process and enhancing osteogenesis, potentially providing new ideas for the treatment of periprosthetic osteolysis (Scheme 1).

\section{Materials and Methods}

\section{Particle Generation}

UHMWPE particles (Shamrock, TEDA, Tianjin, China) ranging from $0.5-5 \mu \mathrm{m}$ in size were utilized in the study because wear particles in this size range cause obvious macrophage-mediated inflammation. ${ }^{25}$ The particles had a mean diameter of $3.8 \mu \mathrm{m}$ according to scanning electron microscopy (SEM).

The particles were first resuspended in $70 \%$ and $100 \%$ ethanol and then sterilized with cobalt- $60 \gamma$ radiation under a vacuum. The density of the UHMWPE particles was $0.97 \mathrm{~g} / \mathrm{cm}^{3}$; thus, these white micronized powder particles were first suspended in absolute ethanol. The endotoxin level in the particle suspension was measured using a BIOENDO Endotoxin Quantitation Kit (Xiamen Bioendo Technology Co., Ltd., Xiamen, China). The size distribution and zeta potential of the UHMWPE particles were determined with a Nanosizer ${ }^{\mathrm{TM}}$ instrument (Malvern Instruments, Malvern, UK).

\section{Mouse Macrophage Culture and Coculture of Macrophages and PE Particles}

RAW264.7 cells were purchased from the Advanced Research Center, Central South University. RAW264.7 cells were cultured in high-glucose DMEM (Shanghai BasalMedia Technologies Co., Shanghai, China) containing $10 \%$ fetal bovine serum (FBS; Gibco, USA) and $1 \%$ penicillin-streptomycin (Gibco, USA) at $37^{\circ} \mathrm{C}$ with $5 \% \mathrm{CO}_{2}$. As noted previously, the density of the UHMWPE particles was less than that of water, and the aseptic UHMWPEs tended to float on the surface after addition to the culture medium, presenting a serious challenge for subsequent cell-based experiments. Numerous studies have utilized different methods to confine UHMWPE particles to the bottom of the well or plate, such as inverted cell culture, but this system has several disadvantages: 1) it increases the probability of cell contamination when the cell culture medium is exchanged, and 2) most importantly, this experimental method is not simple. ${ }^{26,27}$ We therefore suspended sterilized UHMWPE particles in culture medium and then repeatedly dispensed and aspirated the medium with a pipette for $30 \mathrm{~min}$ until the color of the medium became pink.

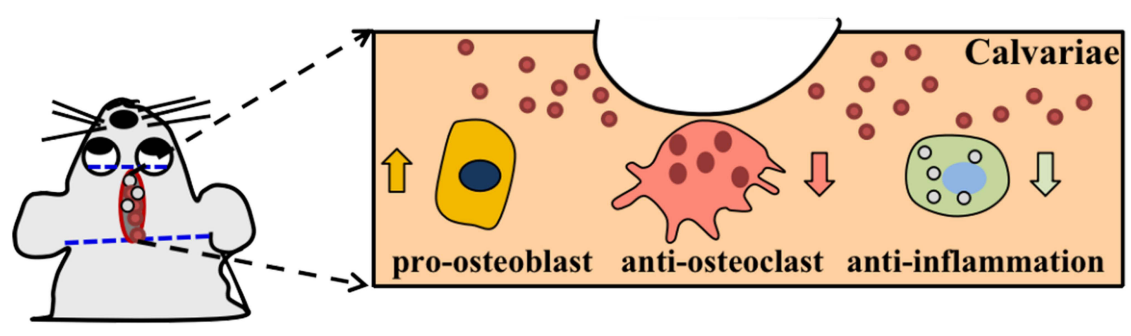

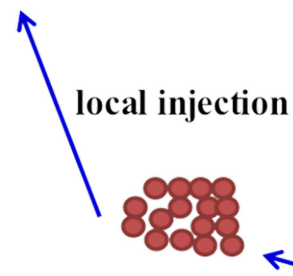

EVs 


\section{Isolation, Culture and Identification of Human USCs}

The methods used to isolate and characterize USCs have been described previously. ${ }^{17,23}$ The collection of urine samples was approved by Medical Ethics Committee of the Xiangya Hospital of Central South University (No. 2019030499). In addition, written informed consent had been provided by the donor. The process used to collect and isolate urinary cells is shown in Supplementary Figure S1. Briefly, midstream human urine samples $(50 \mathrm{~mL})$ from a healthy male donor aged 30 years were collected in a sterile container, after which $500 \mu \mathrm{L}$ of an antibiotic-antimycotic solution (Gibco, USA) were added to the container. The urine was transferred to a sterile $15-\mathrm{mL}$ centrifuge tube and centrifuged at $400 \mathrm{xg}$ for $10 \mathrm{~min}$. The supernatant was discarded, leaving only $1 \mathrm{~mL}$. After PBS was added, the tube was centrifuged at $200 \mathrm{x} g$ for another 10 min, and the supernatant was discarded, leaving only $0.2 \mathrm{~mL}$. The cell pellet was resuspended in primary medium (Lonza, USA) used to culture the USCs and transferred to a 12-well plate. Only USCs at passages 2-6 were used in subsequent experiments.

Osteogenic, adipogenic and chondrogenic differentiation of USCs was induced with special culture medium (Cyagen Biosciences, Guangzhou, China). ${ }^{17,28}$ Surface marker proteins were detected on passage 4 USCs using flow cytometry. FlowJo software (Tree Star Inc., Ashland, USA) was used to analyze the results.

\section{Isolation and Identification of USC-EVs}

USC-EVs were isolated from the culture medium as described in a previous study. ${ }^{17,29}$ The process used to isolate and characterize the USC-EVs is shown in Supplementary Figure S2. After the USCs reached 70$80 \%$ confluence, fresh complete medium (Lonza, USA) containing exosome-depleted FBS (Shanghai VivaCell Biosciences Ltd., Shanghai, China) was added to the flask and incubated with the USCs for $48 \mathrm{~h}$. The culture medium was collected and sequentially centrifuged at 300 $\times \mathrm{g}$ for $10 \mathrm{~min}, 2000 \times \mathrm{g}$ for $30 \mathrm{~min}$, and $4000 \times \mathrm{g}$ for 30 min. Then, we filtered the supernatant, added the supernatant to an Amicon Ultra15 centrifugal filter tube (10 $\mathrm{kDa}$; Millipore, USA) and centrifuged the tube at $4000 \times$ g. After ExoQuick-TC (System Biosciences, USA) was added to the solution, the mixture was incubated for at least $12 \mathrm{~h}$ and centrifuged at $1500 \times \mathrm{g}$ for $30 \mathrm{~min}$, leaving the EV pellet at the bottom of the tube. An appropriate volume of PBS was added to resuspend the EV pellet. The protein content of EVs was determined with a BCA Protein Assay Kit (Multi Sciences LTD., Hangzhou, China). All procedures were performed at $4^{\circ} \mathrm{C}$.

Western blot analysis was used to determine the expression of TSG101 (ab125011, 1:1000, Abcam), CD63 (sc-5275, 1:500, Santa, USA) and calnexin (ab22595, 1:1000, Abcam, USA). ${ }^{17,30}$ The cell extract was used as a control. The size distribution of EVs was measured using DLS (Malvern Instruments, Malvern, UK). The morphology of EVs was determined under a TEM (Hitachi H7500 TEM, Tokyo, Japan). ${ }^{17,31}$

\section{USC-EV Uptake Assay}

We stained the EVs with the fluorescent dye PKH26 (Sigma, USA) to observe whether RAW264.7 cells took up the USC-EVs. Briefly, $1.0 \mathrm{~mL}$ of Diluent $\mathrm{C}$ was added to the EV solution $(800 \mu \mathrm{g})$. Then, $4 \mu \mathrm{L}$ of PKH26 dye were added to the mixture and incubated with the EVs for $5 \mathrm{~min}$ at room temperature in the dark. Cells were seeded on glass coverslips pretreated with TC (Solarbio, Beijing, China) and cultured for $24 \mathrm{~h}$ until they reached $80-90 \%$ confluence. We then cocultured $25 \mu \mathrm{L}(100 \mu \mathrm{g})$ of USCEVs with RAW264.7 cells in serum-free medium. Images were captured with a fluorescence microscope (Leica, Germany).

\section{Osteoclast Differentiation Assay}

RAW264.7 osteoclast progenitor cells $\left(1.0 \times 10^{4}\right.$ cells per well) were seeded into 48-well plates and incubated overnight. Then, the medium was exchanged, and the cells were classified into three groups: the 1) vehicle group (DMEM + PBS), 2) UHMWPE + RANKL + vehicle group (DMEM + UHMWPE + RANKL + PBS), and 3) UHMWPE + RANKL + USC-EVs group (DMEM + UHMWPE + RANKL + USC-EVs). The medium was exchanged for fresh high-glucose DMEM or DMEM + UHMWPE particles containing $100 \mathrm{ng} \cdot \mathrm{mL}^{-1} \mathrm{RANKL}$ (ProteinTech, Chicago, USA) and $300 \mu \mathrm{g} \cdot \mathrm{mL}^{-1}$ USCEVs or vehicle (PBS). After coculture for 7 days, the cells were stained with a commercial TRAP Kit (Sigma, USA), and the $\mathrm{TRAP}^{+}$osteoclasts ( $>3$ nuclei) in each well were counted under an inverted microscope (Leica, Germany). After 4 days of induction, the original medium was collected and used for ELISAs.

\section{Osteogenic Differentiation Assay}

BMSCs were isolated from the femurs and tibias of 4-week-old male C57BL/6 mice. BMSCs were seeded 
into 48-well plates, and $24 \mathrm{~h}$ later, the old culture medium was changed to osteogenesis induction medium (Cyagen Biosciences Inc., Guangzhou, China) containing UHMWPE particles $(1.0 \mathrm{mg} / \mathrm{mL})$ with or without USCEVs $(100 \mu \mathrm{g} / \mathrm{mL})$. Four days later, conditioned medium (CM) was obtained and assayed with an alkaline phosphatase (ALP) assay kit and calcium assay kit according to the manufacturer's instructions (Nanjing Jiancheng Bioengineering Institute, Nanjing, China). After 12 days of induction, the cells were fixed and stained with an Alizarin Red S (ARS) solution (Cyagen Biosciences Inc., Guangzhou, China). Images were captured under an inverted microscope (Leica DMI6000B, Solms, Germany).

\section{Western Blotting}

For Western blotting, $5 \times$ protein loading buffer (Beyotime Biotechnology, Jiangsu, China) was added to the lysates of USCs or USC-EVs, and the mixtures were added to a $12 \%$ SDS-PAGE gel for subsequent electrophoresis and protein transfer to a membrane. The following primary antibodies were used at the indicated dilutions: anti-CD63 (sc-5275; 1:500; Santa Cruz, USA), anti-TSG101 (ab125011; 1:1000; Abcam, USA) and anti-calnexin (ab22595; 1:1000; Abcam, USA). All secondary antibodies (1:5000) were purchased from Cell Signaling Technology. The protein bands were imaged with a ChemiDoc XRS Plus luminescence image analyzer (Bio-Rad, USA).

\section{UHMWPE Particle-Induced Calvarial Osteolysis Model and Surgical Treatment} The experimental procedures were approved by the Department of Laboratory Animal Management Committee of Central South University (No. 2020sydw0972) and was conducted according to the principles of Laboratory Animal Guidelines for ethical review of animal welfare (GB/T 35892-2018). Thirty female BALB/c mice (8-10 weeks old) were purchased from Hunan SJA Laboratory Animal Company (Changsha, China). The weight of each mouse was approximately 20 $24 \mathrm{~g}$ before the experiment. The in vivo calvarial osteolysis model was established using methods reported in previously published articles with slight modifications. ${ }^{32}$ Briefly, the mice were anesthetized via an intraperitoneal injection of pentobarbital $(50 \mathrm{mg} / \mathrm{kg})$. After the skin on the calvariae along the midline had been incised, $30 \mathrm{mg}$ of UHMWPE particles were added to the surface of the bilateral parietal bones, after which the wound was closed using 4-0 Prolene sutures. Thirty mice were randomly assigned to three experimental groups of 10 mice each: the vehicle control group (sterile PBS), UHMWPE group, and UHMWPE + USC-EVs group $(200 \mu \mathrm{g}, 100 \mu \mathrm{L})$. After a subcutaneous postoperative injection of USC-EVs into the center of the calvariae, $2 \mu \mathrm{g} / \mu \mathrm{L}$ USC-EVs were administered by injection once a week three additional times, and the control mice were locally injected with PBS (100 $\mu \mathrm{L}$, the vehicle for the USC-EVs). Twenty-eight days after the operation, the mice were sacrificed in a carbon dioxide chamber, and their calvariae were harvested, fixed with $4 \%$ PFA for 2 days, and then stored in PBS at $4{ }^{\circ} \mathrm{C}$ until analysis.

\section{In vivo Fluorescence Imaging to Detect the Biodistribution of USC-EVs}

USC-EVs $(800 \mu \mathrm{g})$ were incubated with DiR (D12731, Thermo Fisher Scientific) for $20 \mathrm{~min}$ in a final volume of $500 \mu \mathrm{L}$ at $37^{\circ} \mathrm{C}$ in the dark. The USC-EVs were then washed with PBS and processed as described for the PKH26 dye. BALB/c mice were anaesthetized with an intraperitoneal injection of pentobarbital $(50 \mathrm{mg} / \mathrm{kg})$, and DiR-labeled USC-EVs $(n=3)$ or PBS $(n=3)$ were subcutaneously injected into the center of the calvariae. Fluorescence images were obtained after 1, 3, 6, 8, 10, 13 and 15 days with a fluorescence tomography imaging system (FMT-4000; PerkinElmer, USA). Then, the mice were sacrificed, and the major organs were obtained for further fluorescence image scanning.

\section{Microcomputed Tomography $(\mu \mathrm{CT})$ Analysis}

High-resolution $\mu$ CT (SkyScan 1176; SkyScan, Aartselaar, Belgium) was utilized to quantitatively evaluate bone mass. The scanning current, voltage, and resolution were set to $400 \mu \mathrm{A}, 50 \mathrm{kV}$ and $8.88 \mu \mathrm{m}$ per pixel, respectively. One hundred consecutive images in the center of each bone were captured, and a region of interest (ROI) was defined for the quantitative analysis as described a previously published study. ${ }^{32}$ CTAn software (SkyScan, Aartselaar, Belgium) was used to observe the twodimensional (2D) images of each calvaria and to calculate the ratio of bone volume to total tissue volume (BV/TV). Three-dimensional (3D) images were reconstructed using Mimics v10.01 software (Materialise, Leuven, Belgium). Image-Pro Plus 6.0 software was used to calculate the number of pores and percentage porosity. 
Histological and Immunohistochemical Analyses

After $\mu \mathrm{CT}$ scanning, the bones were decalcified in $10 \%$ EDTA ( $\mathrm{pH}$ 7.4) for 7 days. Coronal sections $(5 \mu \mathrm{m})$ in the middle of the calvaria were subjected to H\&E staining to evaluate the degree of bone erosion. We selected and evaluated three separate sections per sample in a blinded manner. Additionally, we regarded the areas with discontinuous and nonosseous tissues as areas of osteolysis. The periosteum thickness $(\mathrm{mm})$ was measured and quantified. A commercial TRAP staining kit (Sigma-Aldrich, USA) was used to evaluate the number of osteoclasts in the bone. The ratio of the osteoclast surface to the total bone surface was calculated for each sample. Image-Pro Plus 6.0 software was utilized to analyze the captured digital photographs.

For OCN and TNF- $\alpha$ immunohistochemical staining, the sections were rehydrated and heated in a microwave. Then, the sections were incubated with the primary antiOCN (1:100; Abcam, USA) or anti-TNF- $\alpha$ (1:500; Abcam, USA) antibody overnight at $4{ }^{\circ} \mathrm{C}$, followed by an incubation with the secondary antibody (1:250; Abcam, USA) at room temperature for $1 \mathrm{~h}$ in the dark. Images were captured with a light microscope (Olympus CX31, Japan). The staining intensity and number of positively stained cells were measured using Image-Pro Plus 6.0 software.

\section{Safety Examination}

Blood was collected after anesthesia and subsequently analyzed by performing a routine blood examination. $H \& E$ staining of the major organs was performed after the blood had been collected.

\section{Enzyme-Linked Immunosorbent Assay (ELISA)}

A commercial mouse TNF- $\alpha$ ELISA kit (ab208348, Abcam, USA) and mouse IL-6 ELISA kit (ab222503, Abcam, USA) were utilized to measure the concentrations of TNF- $\alpha$ and IL- 6 in the culture medium. A microplate reader (Bio-Rad 680, USA) was used to measure the OD (optical density) value at $450 \mathrm{~nm}$.

\section{Statistical Analyses}

The data are presented as the means \pm standard deviations (SD). Statistical analyses were carried out to assess the significance of differences using one-way analysis of variance (ANOVA). All analyses were performed using SPSS
19.0 software (SPSS Inc., Chicago, IL, USA). P value $<0.05$ was indicated as statistical significance.

\section{Results UHMWPE Particle Characterization}

The morphology, size distribution and zeta potential of UHMWPE particles were determined using SEM and DLS (Figure 1A-C). SEM images showed that the particles had an irregular shape and rough surface (Figure 1A). Based on their size distribution, over $90 \%$ of the particles were $0.5-5 \mu \mathrm{m}$ in size (Figure 1B). The zeta potential was "slightly negative" (Figure 1C), which is ideal for cytophagy. The endotoxin curve is presented in Figure 1D; the endotoxin concentration in UHMWPE particles detected at $2 \mathrm{~h}$ was $0.052 \mathrm{EU} / \mathrm{mL}$.

\section{Characterization of USCs and USC-EVs}

Small, single cells were observed 4 days after initial seeding into a 12-well plate (Supplementary Figure S3). Nine days after the cells were plated, a cell cluster appeared on the plate (Supplementary Figure S3). Twelve days later, the mature, spindle-like cells underwent rapid proliferation and quickly achieved $80-90 \%$ confluence (Supplementary Figure S3). The adherent cells exhibited a spindle-like morphology (Figure 2A). As shown in Figure 2B, after induction in special culture medium, the USCs underwent osteogenic, adipogenic or chondrogenic differentiation, as indicated by positive ARS (Figure 2B-a), Oil Red O (Figure 2B-b) and toluidine blue (Figure 2B-c) staining, respectively. In addition, cell counting kit-8 (CCK-8) assay results revealed that the cells underwent rapid growth in the period from day 3 to 7 , followed by stable growth in the period after day 7 (Figure 2C). Flow cytometry results showed that the USCs were positive for CD29, CD44, CD73 and CD90 but negative for CD34 and CD45 (Figure 2D). Based on these data, the cells isolated from human urine samples were classified as MSCs. ${ }^{17,20,33,34}$ The morphology of the EVs was verified using TEM (Figure 2E), and the TEM images revealed the cup-like morphology and double-layered membrane structure of the extracellular particles, similar to previously described results. ${ }^{13,17,35}$ Western blot analysis revealed that the USC-EVs were positive for the exosome-specific markers CD63 and TSG101 but negative for calnexin (Figure 2F). DLS results showed that the particles were mainly 30 to $150 \mathrm{~nm}$ in size (Figure $2 \mathrm{G}$ ), consistent with previous reports. ${ }^{13,17,35}$ 


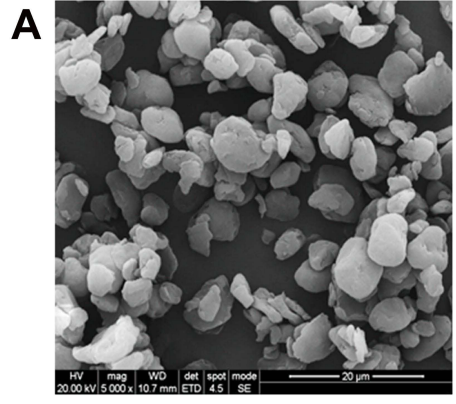

C

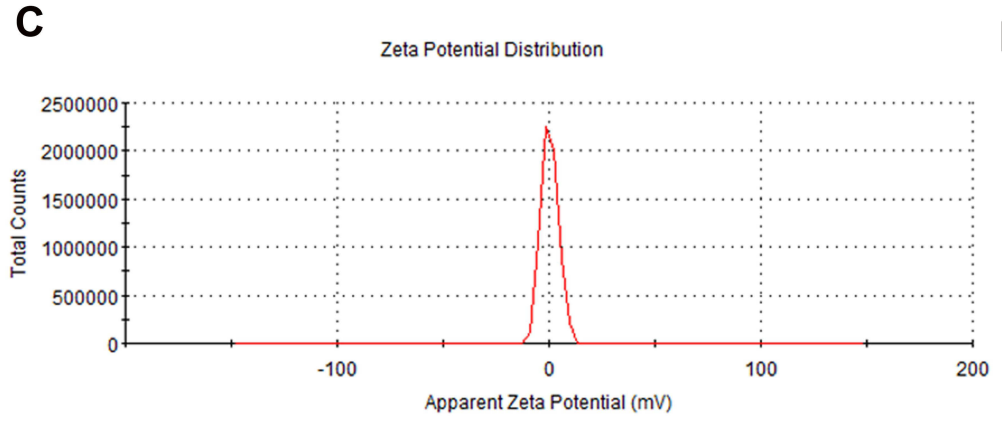

Size Distribution by Intensity

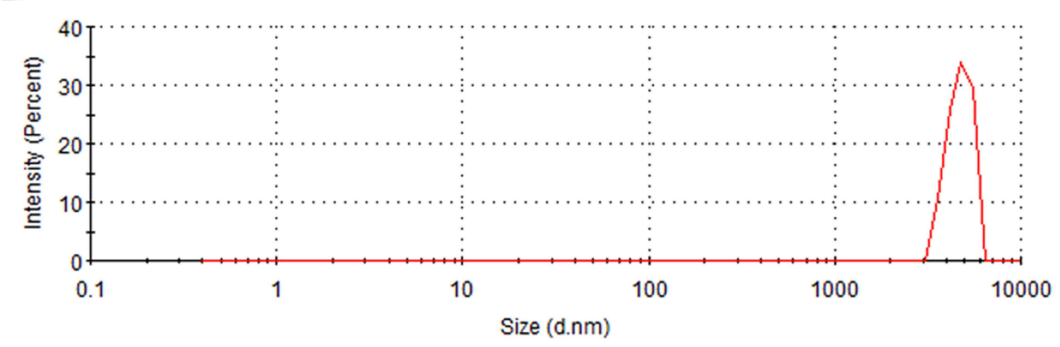
The size distribution and zeta potential of UHMWPE microparticles were analyzed using DLS. (D) Curve showing the endotoxin concentration in UHMWPE.
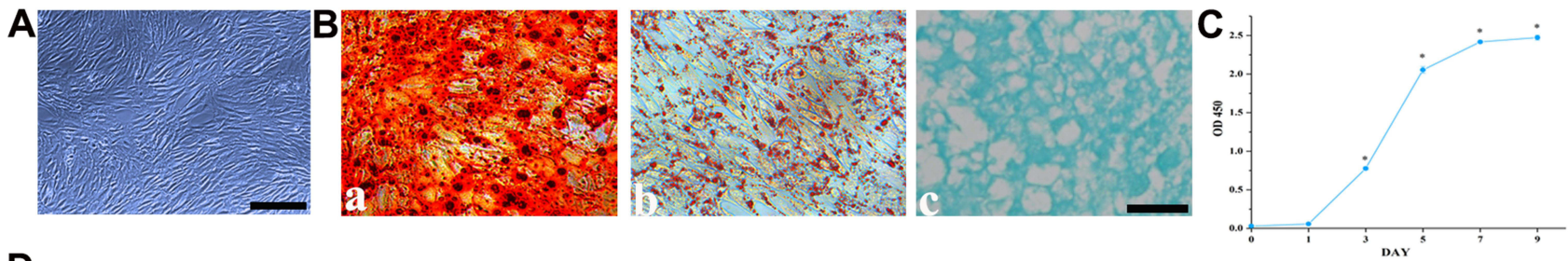

D

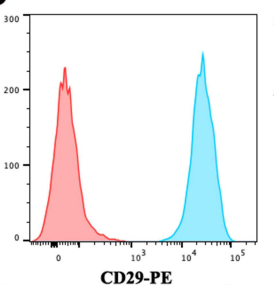

E

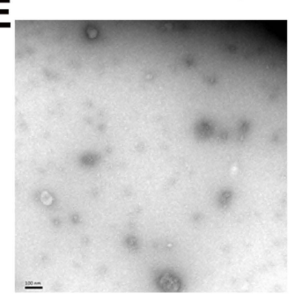

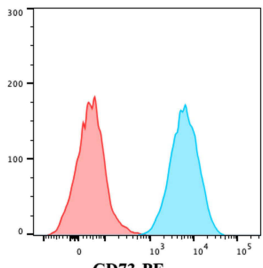

F

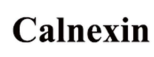

CD63

TSG101

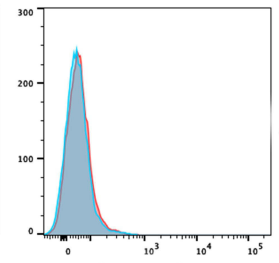

CD34-FITC

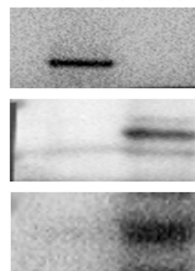

D

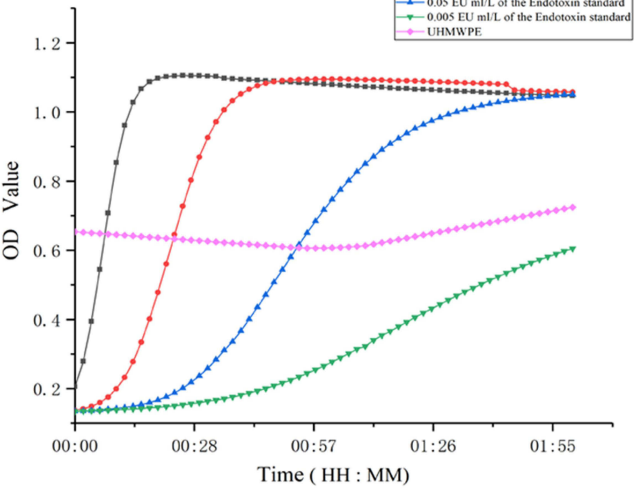




\section{Internalization of EVs by RAW 264.7 Cells}

We cocultured PKH-26-labeled EVs with RAW264.7 cells to explore their potential uptake by these cells. After 24 $\mathrm{h}$ of coculture, fluorescence imaging (Figure 3A) showed that the PKH-26-labeled USC-EVs (red dots) had been endocytosed and were distributed near the perinuclear region of the RAW264.7 cells.

\section{USC-EVs Inhibited Osteoclast Formation and Reduced Inflammatory Cytokine Levels}

RAW264.7 cells were cultured with $1 \mathrm{mg} / \mathrm{mL}$ UHMWPE particles, and the following results were obtained: (1) RAW264.7 cells phagocytosed the particles (dark dots, Figure 3B), and (2) the concentration of the particles did not substantially influence cell viability (Figure 3C).

RAW264.7 cells were stimulated with RANKL and treated with USC-EVs or PBS for 7 days to observe the effect of
USC-EVs on osteoclast formation and the protein levels of inflammatory cytokines. RAW264.7 cells cultured with RANKL and UHMWPE particles exhibited a large number of TRAP-positive osteoclasts, whereas the USC-EV treatment suppressed osteoclast formation, as identified by TRAP staining (Figures 3D and E). ELISA results showed higher concentrations of TNF- $\alpha$ and IL- 6 in CM from the RANKL + UHMWPE groups than those in CM from the vehicle group, and USC-EV treatment obviously decreased TNF- $\alpha$ and IL-6 production (Figure 3F). Our results suggest that USC-EVs inhibit osteoclast formation by decreasing the concentrations of inflammatory cytokines.

\section{USC-EVs Enhanced Osteogenic Activity}

BMSCs were cultured in osteogenic induction medium containing USC-EVs or PBS in vitro to observe the effects of USC-EVs on osteogenesis. USC-EVs obviously promoted the formation of calcium nodules, as evidenced by ARS staining (Figure 3G). After 4 days of induction, the
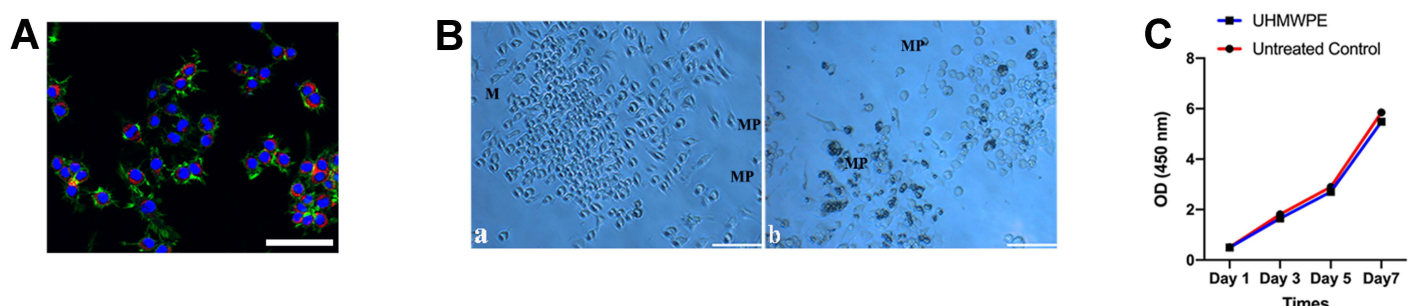

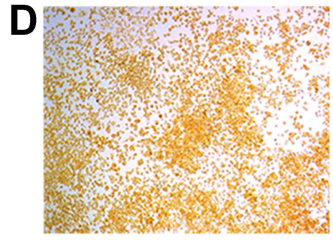

Vehicle

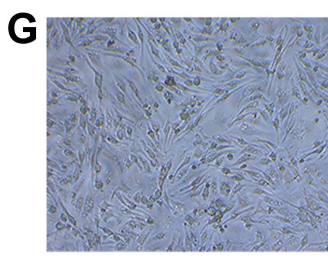

BMSCs

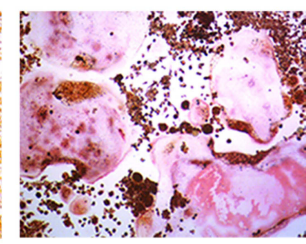

PE + RANKL + PBS

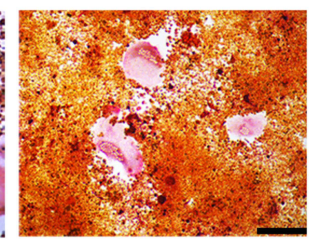

PE + RANKL + EVs

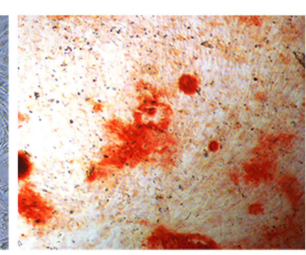

Vehicle + PE

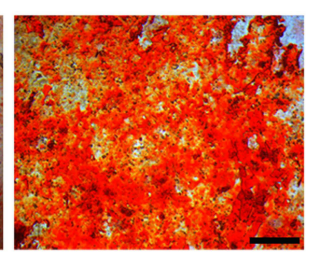

USC-EVs + PE

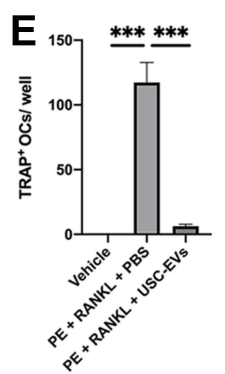

H

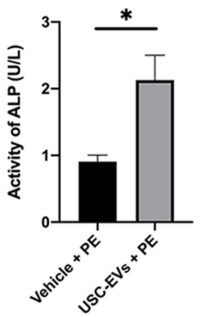

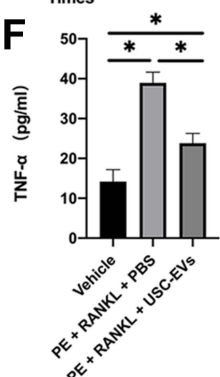
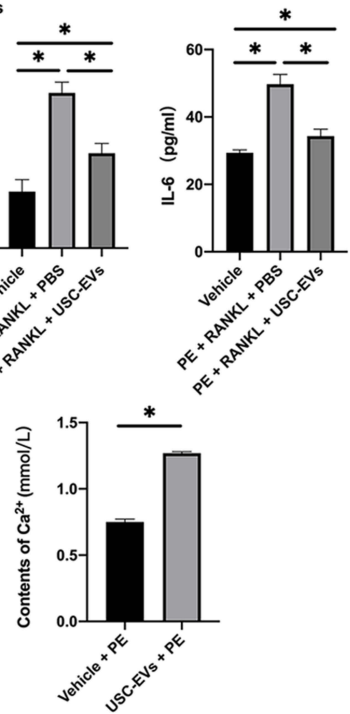

Figure 3 USC-EVs inhibit the osteoclast differentiation of RAW264.7 cells and promote the osteogenic differentiation of BMSCs. (A) Representative immunofluorescence images showing the internalization of PKH26-labeled USC-EVs (red) by RAW264.7 cells stained with phalloidin (green). The cell nuclei of RAW264.7 cells were stained with DAPI (blue). Scale bar: $50 \mu \mathrm{m}$. (B) UHMWPE particles (dark dots, MPs) were internalized into macrophages (M). (C) Macrophages exposed to UHMWPE particles for 7 days. Macrophage proliferation was measured at I, 3, 5 and 7 days. (D) Osteoclast differentiation of RAW264.7 cells was determined using TRAP staining. Scale bar: $200 \mu$ m. (E) The number of $\mathrm{TRAP}^{+}$multinucleated (> 3 nuclei) osteoclasts in each well of a 48 -well plate was determined. $\mathrm{n}=3$ samples per group. $* * * \mathrm{P}<0.00 \mathrm{I}$. (F) The concentrations of TNF- $\alpha$ and IL- 6 in conditioned medium from RAW264.7 cells receiving different treatments were determined with ELISAs. $n=3$ samples per group. $* \mathrm{P}<0.05$. (G) ARS of BMSCs receiving different treatments under osteogenic induction conditions. (H) Quantitative analyses of ALP and Ca ${ }^{2+}$ levels in conditioned medium from BMSCs receiving different treatments. $\mathrm{n}=3$ samples per group. $* \mathrm{P}<0.05$. 
concentrations of ALP and $\mathrm{Ca}^{2+}$ in the $\mathrm{CM}$ from the different groups were analyzed (Figure $3 \mathrm{H}$ ). As shown in Figure $3 \mathrm{H}$, USC-EVs enhanced matrix mineralization, and the concentrations of ALP and $\mathrm{Ca}^{2+}$ were significantly higher than those in the vehicle group. The ALP, $\mathrm{Ca}^{2+}$ and ARS staining results showed that USC-EV treatment significantly stimulated the osteogenic differentiation of BMSCs.

\section{Biodistribution of USC-EVs in a Murine Calvarial Osteolysis Model}

We first established a mouse model of calvarial bone resorption and then subcutaneously injected DiR-labeled EVs into the central region of the calvariae to investigate the local biodistribution of the USC-EVs. The mice were imaged using an IVIS system at the indicated time points, and we found that the fluorescence intensity of the DiRlabeled USC-EVs gradually decreased over 2 weeks; however, fluorescence was still detected locally in the calvariae at the end point (Figures 4A and B). Then, the major organs, including the calvariae, were removed and observed. We did not detect DiR-labeled USC-EVs in the lungs, hearts, livers, spleens, or kidneys of the treated animals, but DiR-labeled USC-EVs were detected in the calvariae (Figure 4C). Thus, the locally injected USC-EVs are maintained for approximately 2 weeks.

\section{USC-EVs Prevented UHMWPE} Particle-Induced Osteoclastic Bone

\section{Resorption}

We examined the effect of USC-EVs on a UHMWPE particle-induced murine calvarial osteolysis model in vivo. As shown in Figure 5A, gross pathology verified that the UHMWPE particles stimulated a pronounced inflammatory response in the calvariae. By performing $\mu \mathrm{CT}$ scans and $3 \mathrm{D}$ reconstructions, we observed extensive calvarial resorption in the UHMWPE group, which also showed a substantial increase in surface erosion on the bone compared with that in the negative control group (sham; PBS injection) (Figure 5B). Nevertheless, treatment with USC-EVs inhibited UHMWPE particleinduced osteolysis (Figure 5B). Quantification of bone parameters confirmed that USC-EV treatment significantly increased the $\mathrm{BV} / \mathrm{TV}$ ratio (Figure $5 \mathrm{C}$ ) and reduced the number of pores and porosity percentage (Figures 5D and $\mathrm{E})$.

H\&E staining revealed slight osteolytic changes in the control group. In contrast, the UHMWPE group showed clear osteolysis, while the USC-EV treatment groups showed reduced osteolysis (Figure 6A); additionally, the area of eroded bone surface and the periosteal thickness were smaller than those in the UHMWPE particle-induced

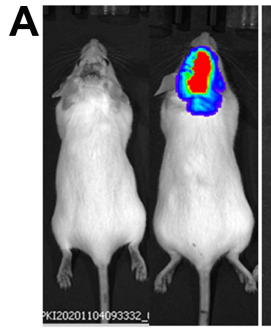

$$
\text { PBS } \begin{gathered}
\text { Day } 1 \\
\text { EVs }
\end{gathered}
$$

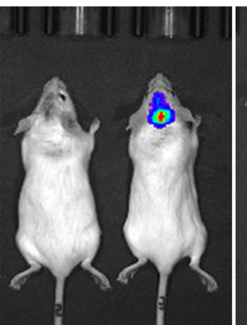

Day 3 PBS EV

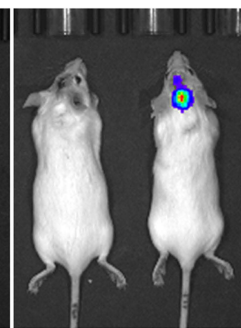

Day 6 PB

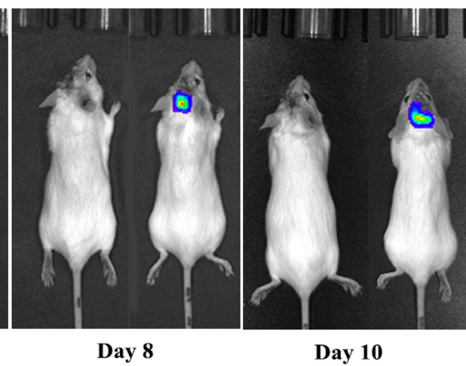

PBS

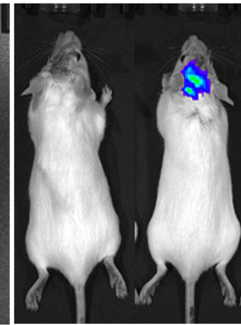

Day 13 PBS
B

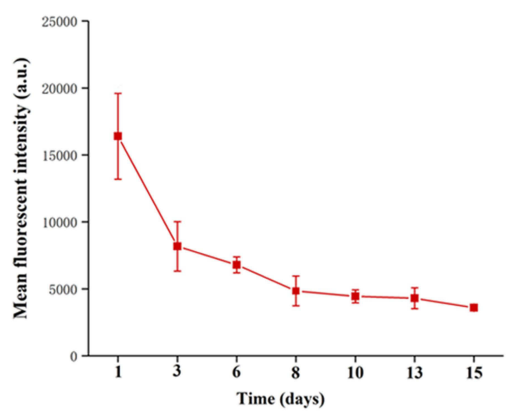

C

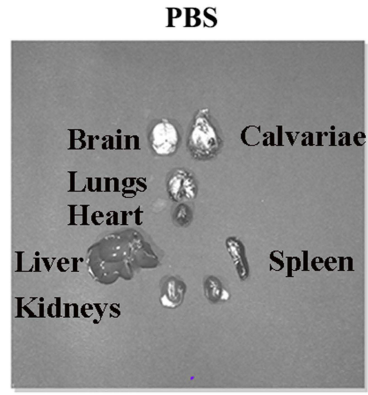

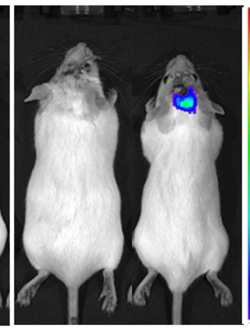

Day 15 PBS EVs

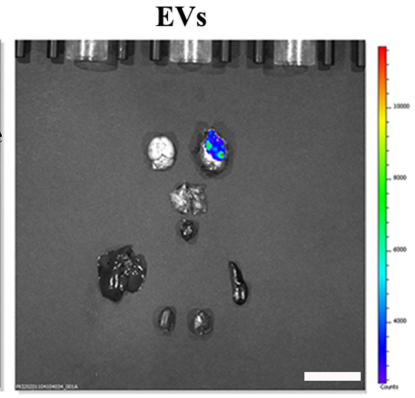

Figure 4 USC-EV accumulation in mice. (A) DiR-labeled USC-EVs were locally injected into the center of the calvariae, and then the mice were imaged with an IVIS system at the indicated time points. (B) Quantitative analysis of the fluorescence intensities shown in A; $n=3$ animals per group. (C) Fifteen days after injection, the mice were sacrificed, and major organs (calvariae, heart, lungs, liver, spleen and kidneys) were removed for imaging. Scale bar: $50 \mu \mathrm{m}$. 
A

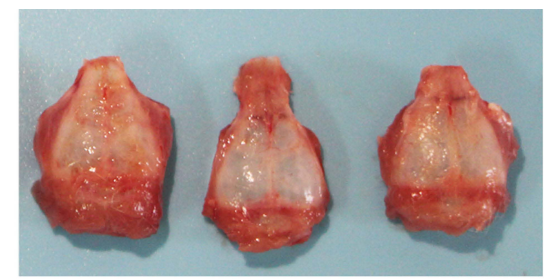

Control

B
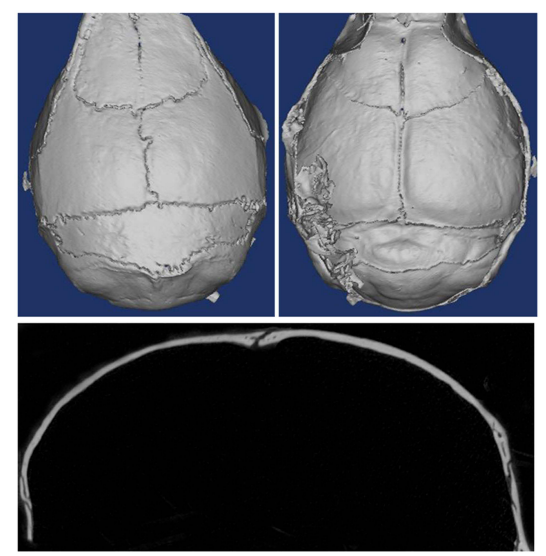

Control

C

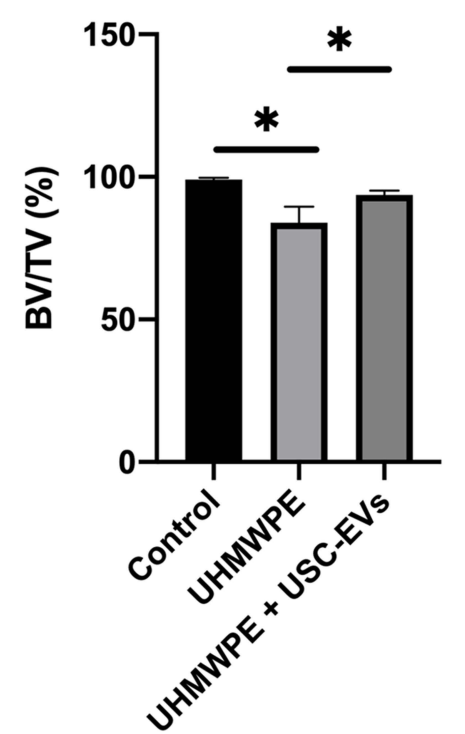

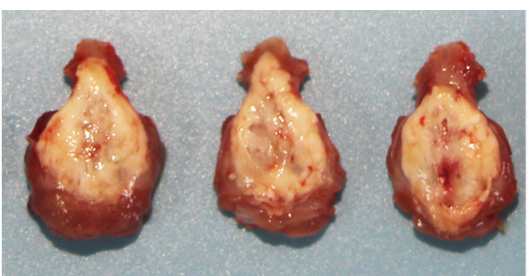

UHMWPE
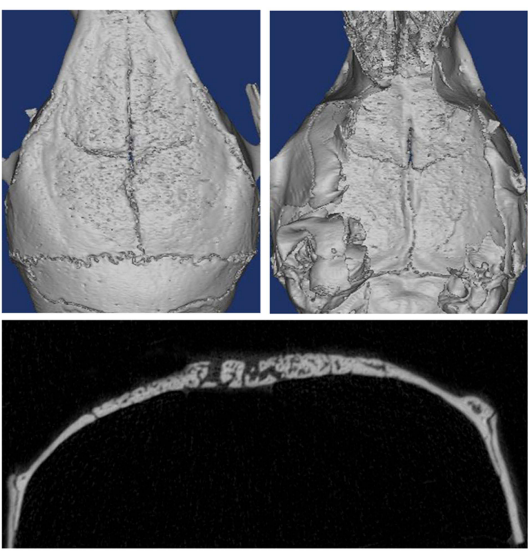

UHMWPE

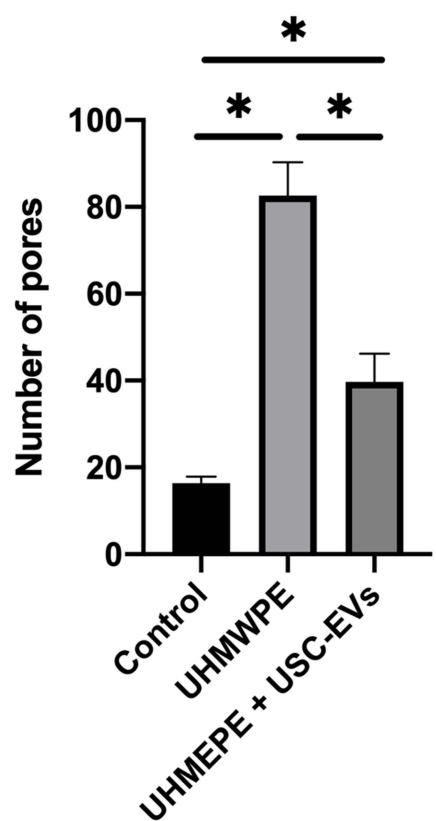

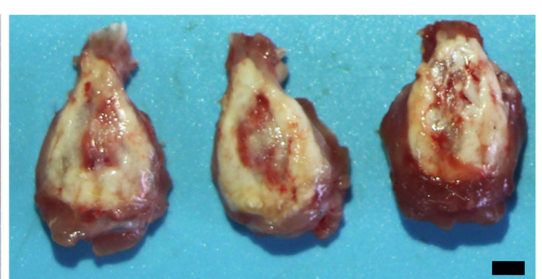

UHMWPE + USC-EVs
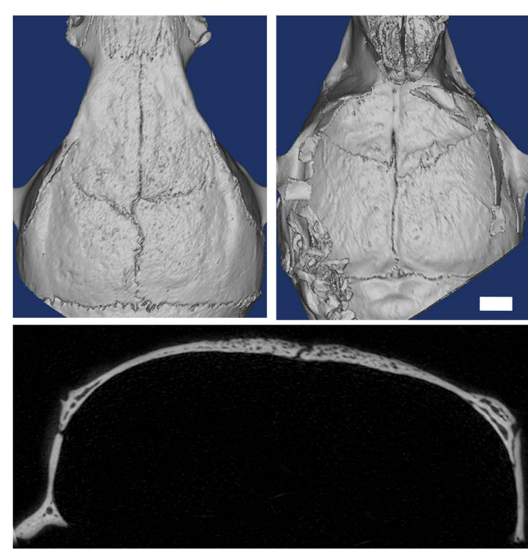

UHMWPE + USC-EVs

E

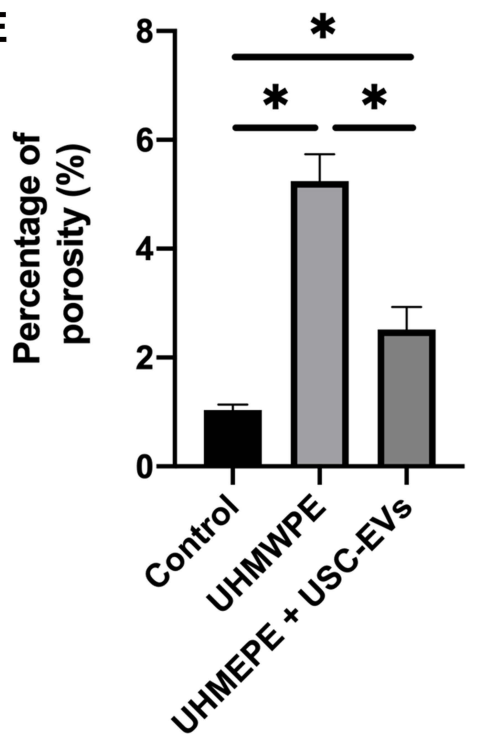

Figure 5 USC-EVs attenuate bone loss in osteolysis mice. (A) Typical macroscopic appearance of the calvarium dissected from mice at 4 weeks after the operation. (B) Representative $\mu$ CT surface images of the calvarial bone among groups. $n=8$ animals per group. Quantitative analyses of the BV/TV (C), number of pores (D) and percentage of porosity (E); $\mathrm{n}=4$ or 5 animals per group. $* \mathrm{P}<0.05$. Scale bar: $30 \mu \mathrm{m}$.

group (Figures 6B and $\mathrm{C}$ ). In addition, the histomorphometric analysis indicated that USC-EVs reduced bone erosion, consistent with the results of quantitative $\mu \mathrm{CT}$ analyses. The number of TRAP ${ }^{+}$osteoclasts on the eroded bone surface was increased following the introduction of UHMWPE particles. However, in the USC-EV treatment group, the total number of TRAP-positive osteoclasts and the percentage of osteoclast surface over the bone surface were reduced (Figure 6D-F), indicating that the USC-EV treatment effectively suppressed osteoclastogenesis during UHMWPE particle-induced osteolysis in vivo. The results of immunohistochemical staining are shown in Figure 6D. The osteogenic marker OCN was expressed at high levels in the USC-EV treatment group (Figure 6G). In addition, 


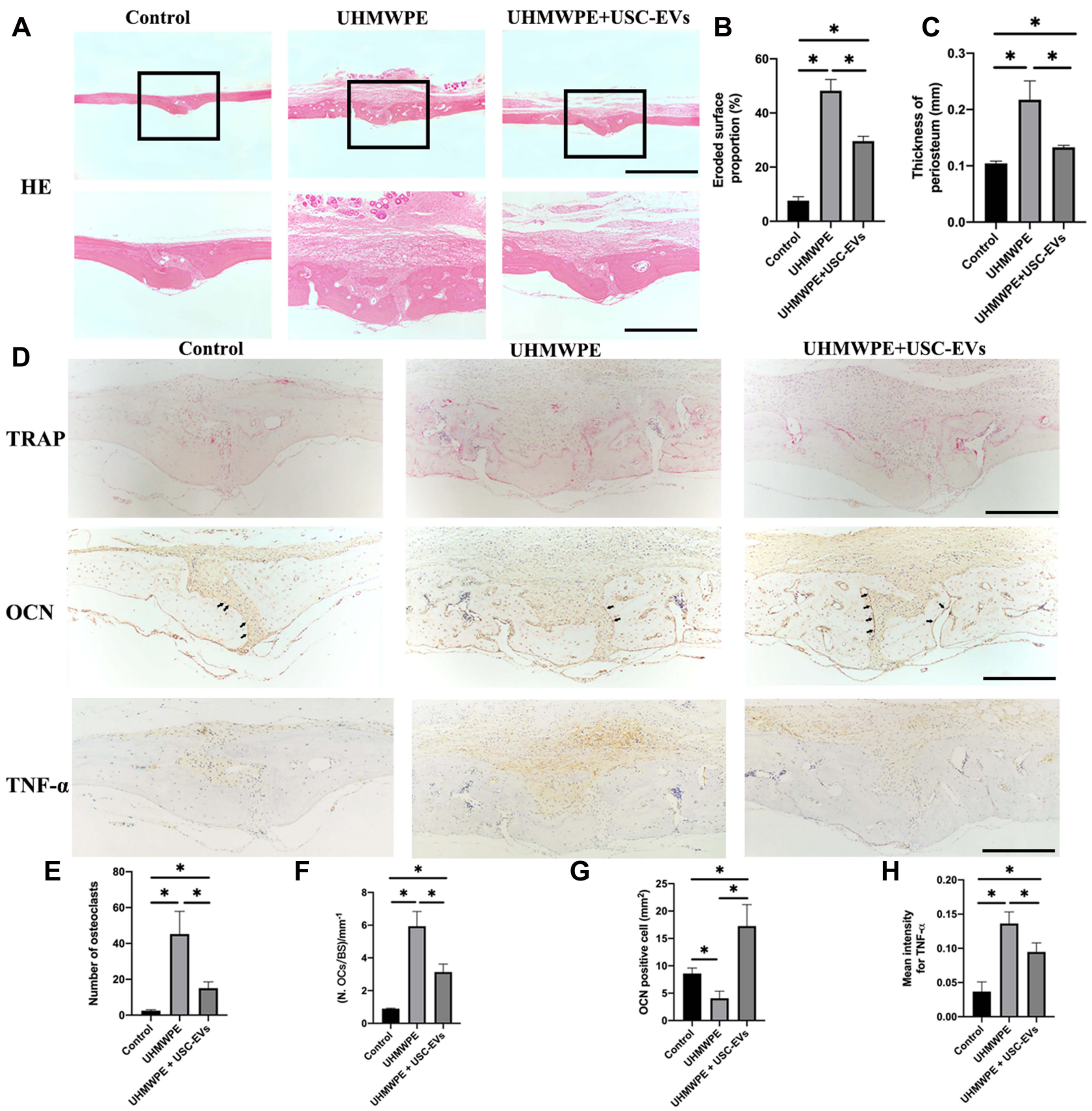

Figure 6 USC-EVs inhibit inflammatory and osteoclastic activities and promote osteogenesis in vivo. (A) H\&E staining of the calvarial tissue sections. Scale bar: I00 $\mu$ m. Quantitative analyses of the (B) eroded surface area and (C) periosteum thickness in each group. $n=4$ or 5 animals per group. *P $<0.05$. (D) Representative images of TRAP, OCN and TNF- $\alpha$ staining in vivo. Scale bar: $100 \mu \mathrm{m}$. Quantitative analyses of the number of (E) TRAP ${ }^{+}$osteoclasts and (F) the percentage of osteoclast surface over bone surface (OCs/BS, \%). Quantitative analysis of OCN (D, indicated by black arrows) and TNF- $\alpha(\mathbf{H})$ expression in each sample ( $\mathrm{n}=4$ or 5 animals per group). $* \mathrm{P}<0.05$.

decreased TNF- $\alpha$ expression levels were observed in the USC-EV treatment group (Figure 6H).

\section{Safety of USC-EVs}

A major concern regarding the application of EVs from human urine samples is immunogenicity. The safety of the USC-EV application was determined by performing a routine blood examination and H\&E staining of the major organs (Supplementary Figure S4). The numbers of red blood cells, white blood cells and platelets were not obviously different between the different groups (Supplementary Figure S4A). In addition, the proportions of different types of white blood cells showed no significant differences (Supplementary Figure S4B). The hemoglobin (HGB) level and mean corpuscular hemoglobin concentration (MCHC) were similar between the different 
groups (Supplementary Figure S4C), suggesting that the USC-EVs did not influence erythrocyte function. H\&E staining of the major organs further showed no evident pathological differences between the groups (Supplementary Figure S4D).

\section{Discussion}

TJA is widely used to cure serious joint diseases. However, periprosthetic osteolysis and aseptic loosening after TJA are complex problems that require a meticulous evaluation and preoperative planning. Wear particles exert a major effect on biological parameters at the bone-prosthesis interface and are responsible for the most severe adverse events in patients undergoing TJA. In addition, UHMWPE particles produced by prostheses are increasingly presumed to stimulate inflammatory reactions and osteolysis, ${ }^{32,36,37}$ which clearly cause TJA failure. The goal of revision surgery after TJA is to repair bone defects and restore joint stability. However, revision surgery is accompanied by a high morbidity rate and an additional financial burden to the health system. ${ }^{38,39}$ In the present study, we found that USC-EVs obviously promoted osteoblast formation and inhibited osteoclast formation in vitro. We also report that USC-EV treatment decreased inflammatory cytokine levels compared with levels in the control group. In vivo, a subcutaneous injection of USC-EVs clearly decreased bone mass loss in mice through its ability to reduce osteoclast formation and enhance osteogenic activity. USCs from different age groups (children, middle-aged individuals, and elderly individuals) proliferate stably and can be successfully induced to undergo osteogenesis. ${ }^{40}$ Additionally, Chen et al found that the anti-osteoclastic and pro-osteogenic properties of USC-EVs are not influenced by the donor age. ${ }^{41}$ Therefore, autologous USC-EVs are potentially useful as a new, prospective therapeutic agent to treat periprosthetic osteolysis; thus, patients with aseptic loosening may need to simply collect their own urine for USC harvesting and $\mathrm{EV}$ isolation.

Over the last few decades, researchers and clinicians have focused on the utilization of transplanted stem cells for bone disease treatment. ${ }^{15,41,42}$ Among the various types of pluripotent stem cells, USCs are regarded as one of the most promising sources of stem cells and have excellent therapeutic potential for many bone diseases. ${ }^{24,41}$ Recently, researchers verified that the ability of transplanted stem cells to promote tissue repair and regeneration is not only due to their differentiation into parenchymal cells at the site of injury but also due to paracrine responses that induce endogenous cells to participate in tissue regeneration. ${ }^{11,12,43,44}$
EVs are vital paracrine regulators that can be obtained from multiple cell types and biological fluids, including plasma, milk, amniotic fluid, and pleural effusion. The bioactive components of EVs allow them to accurately bind to recipient cells. Once targeted to recipient cells, EVs stimulate the intracellular signaling response via endocytosis or receptorligand interactions or even fuse with the target cell membrane to transfer their internal components into the target cell cytoplasm, thus influencing the function of the recipient cell. ${ }^{13}$ In animal models, the therapeutic effects of EVs released from stem cells are similar to those of the original cells, ${ }^{45}$ suggesting that EVs are critical mediators of cell-cell communication. As shown in the study by Zhang et al, mesenchymal stromal cell-generated EVs effectively ameliorate functional recovery by promoting angiogenesis and neurogenesis and reducing the inflammatory reaction in rats after traumatic brain injury (TBI). ${ }^{46}$ Qi et al found that MSCderived EVs promote bone healing in calvarial defects in rats with osteoporosis. ${ }^{16}$ Additionally, Hu et al documented that human umbilical cord blood-derived EVs improve bone loss in osteoporotic mice. ${ }^{40}$ Furthermore, Chen et al reported that human USC-derived EVs effectively prevent bone loss and preserve bone mass in ovariectomized mice. ${ }^{41}$ These results provide strong evidence that EVs can be utilized to induce bone formation in individuals with bone diseases. Additionally, while abundant evidence has indicated the therapeutic effect of USCs on tissue regeneration, ${ }^{17}$ only a few studies have focused on the therapeutic uses of USCEVs. In this study, we isolated EVs from human USCs and showed that USC-EVs ameliorate bone mass loss in a mouse model of osteolysis, indicating that USC-EVs may be utilized as a new nonsurgical therapeutic intervention for the treatment of aseptic loosening. The inflammatory response, bone resorption, and foreign body granuloma formation around the bone prosthesis site are the principal pathophysiological mechanisms of aseptic loosening. ${ }^{10}$ Macrophages are a vital cell type that participate in pathophysiological processes; hence, RAW264.7 cells are widely used in cell experiments to evaluate cellular changes after exposure to wear debris. ${ }^{9}$ RAW264.7 cells are also an ideal osteoclast precursor, and once stimulated by the cytokine RANKL, these cells differentiate into osteoclasts. ${ }^{47}$ BMSCs are a major cell type used to observe the effects of therapeutic agents or drugs on bone formation in vitro. ${ }^{48}$ Here, we verified that USC-EVs were internalized by RAW264.7 cells, obviously inhibited the osteoclast differentiation of RAW264.7 cells (as evidenced by a decreased number of osteoclasts), and promoted the osteoblast differentiation of 
BMSCs (as evidenced by ARS staining and increased ALP activity and matrix calcium mineralization). A sufficient blood supply is important for bone formation, ${ }^{49}$ and Chen et al reported that USC-EVs deliver proangiogenic proteins to recipient cells and accelerate angiogenesis. ${ }^{17}$ Therefore, USC-EVs may be an effective therapeutic agent to prevent wear particle-induced osteolysis.

EVs contain many functional proteins and miRNAs, ${ }^{13,17,41,50-53}$ and the substantial enrichment of proteins and miRNAs, such as CTHRC1 and $\mathrm{OPG}^{41}$ CLEC11A ${ }^{50}$ miR-3960, $^{15}$ miR-146a-5p and miR-503$5 \mathrm{p},{ }^{51}$ and miR-31a-5p, ${ }^{53}$ is involved in the regulation of multiple signaling pathways related to bone metabolism during the therapeutic process. Chen et al found that CTHRC1 and OPG are responsible for the antiosteoclastic and pro-osteogenic effects of USC-EVs in vitro. ${ }^{41} \mathrm{Hu}$ et al concluded that EVs derived from human umbilical cord blood enhance the osteogenic differentiation of BMSCs and inhibit osteoclast differentiation by delivering CLEC11A or miR-3960. ${ }^{15,50}$ Additionally, miR-146a-5p, ${ }^{51}$ miR-503-5p, ${ }^{51}$ and miR-31a-5 $\mathrm{p}^{53}$ from EVs exert the same effect. USC-EV proteins or miRNAs contribute to dynamic bone repair and regeneration by influencing the microenvironment at the injured region. These already verified molecular mechanisms are suitable for our study because our research also investigated bone repair and reconstruction. In addition, Xian et al identified that mesenchymal stem cell-derived EVs reduce inflammatory responses. ${ }^{54}$ Some other regulatory mechanisms might contribute to the anti-inflammatory, anti-osteoclast and pro-osteogenic effects because so many functional proteins and many miRNAs are present in EVs. Additionally, multiple signaling pathways are involved in bone metabolism, such as the RANK/c-Fos/NFATc1 signaling pathway, ${ }^{55}$ the JNK/c-Fos-NFATc1 cascade, ${ }^{2}$ and the ERK/c-Fos/NFATc1 signaling pathway. ${ }^{56}$ With the development of proteomic analysis and miRNA microarray assays, many new EV proteins and miRNAs will be identified and verified. At present, researchers are still unable to determine the main effective factor in EVs that regulates bone metabolism. The therapeutic effects of EVs may be attributed to a combination of various EV proteins and miRNAs. However, the main mechanisms still require further exploration to identify new and unreported proteins or miRNAs in our follow-up experiments. We should be more focused on specific EV proteins and miRNAs to provide a comprehensive and detailed explanation of the vital role of EVs in bone metabolism.
Currently, major concerns regarding the use of USCEVs are their immunogenicity and safety. Testing the immunogenicity of USC-EVs will be quite necessary when the utilization of allogeneic USC-EVs is required. The safety of USC-EVs was assessed by testing the function of peripheral blood cells and implementing $\mathrm{H} \& \mathrm{E}$ staining of the major organs. USC-EVs did not obviously stimulate immune reactions in the recipient mice in the present study. However, the lack of data regarding the levels of antibodies against USC-EVs in recipient mice is a limitation of the study. Hence, future studies are needed in which antibodies against USC-EVs are tested to improve USC-EV safety. Additionally, the lack of data regarding the effects of USC-EVs from different age groups (children, middle-aged individuals, and elderly individuals) applied at different concentrations on osteolysis is another limitation of the study, and these variables must be further explored in our follow-up research.

\section{Conclusions}

In conclusion, USC-EVs ameliorate bone loss in a mouse model of osteolysis. Mechanistically, this process may occur through the inhibition of inflammatory cytokine production and osteoclastic activity and the promotion of osteogenic formation. Our data reveal that USC-EVs may be a potential therapeutic agent for orthopedic wear debrisinduced osteolysis.

\section{Abbreviations}

USCs, urine-derived stem cells; EVs, extracellular vesicles; USC-EVs, extracellular vesicles from urine-derived stem cells; MVBs, multivesicular bodies; MSCs, mesenchymal stem cells; PBS, phosphate-buffered saline; FBS, fetal bovine serum; ARS, alizarin red S; CCK-8, cell counting kit-8; H\&E, hematoxylin and eosin; WB, Western blotting; CM, conditioned medium.

\section{Data Sharing Statement}

The data generated or analyzed during this study are included in this article or, if absent, are available from the corresponding authors upon reasonable request.

\section{Ethical Approval and Consent to Participate}

This study was approved by the Department of Laboratory Animal Management Committee of Central South University (No. 2020sydw0972) and was conducted 
according to the principles of Laboratory Animal Guidelines for ethical review of animal welfare $(\mathrm{GB} / \mathrm{T}$ 35892-2018).

\section{Consent for Publication}

All authors have declared their consent for publication.

\section{Acknowledgments}

We sincerely thank Professor Hui Xie and Dr. Chunyuan Chen for providing advice and assistance with the isolation of USCs and USC-EVs and other experiments.

\section{Funding}

This work was supported by the National Natural Science Foundation of China (Grant No. 81974339) and the Science and Technology Plan Project of Hunan Province (Grant No. 2019JJ40499).

\section{Disclosure}

The authors have no conflicts of interest to declare.

\section{References}

1. Tian B, Jiang T, Shao ZY, et al. The prevention of titanium-particleinduced osteolysis by OA-14 through the suppression of the p38 signaling pathway and inhibition of osteoclastogenesis. Biomaterials. 2014;35(32):8937-8950. doi:10.1016/j.biomaterials.2014.06.055

2. Zhang LW, Yang YJ, Liao ZR, et al. Genetic and pharmacological activation of Hedgehog signaling inhibits osteoclastogenesis and attenuates titanium particle-induced osteolysis partly through suppressing the JNK/c-Fos-NFATc1 cascade. Theranostics. 2020;10 (15):6638-6660.

3. Gallo J, Goodman SB, Lostak J, Janout M. Advantages and disadvantages of ceramic on ceramic total hip arthroplasty: a review. Biomed Pap Med Fac Univ Palacky Olomouc Czech Repub. 2012;156 (3):204-212. doi:10.5507/bp.2012.063

4. Thiele K, Perka C, Matziolis G, Mayr HO, Sostheim M, Hube R. Current failure mechanisms after knee arthroplasty have changed: polyethylene wear is less common in revision surgery. $J$ Bone Joint Surg Am. 2015;97(9):715-720. doi:10.2106/JBJS.M.01 534

5. Malchau H, Herberts P, Eisler T, Garellick G, S"oderman P. The Swedish total hip replacement register. $J$ Bone Joint Surg Am. 2002;84(S2):2-20. doi:10.2106/00004623-200200002-00002

6. Camuzard O, Breuil V, Carle GF, Pierrefite-Carle V. Autophagy involvement in aseptic loosening of arthroplasty components. $J$ Bone Joint Surg Am. 2019;101(5):466-472. doi:10.2106/JBJS.18.00479

7. Ingham E, Fisher J. The role of macrophages in osteolysis of total joint replacement. Biomaterials. 2005;26(11):1271-1286. doi:10.1016/j. biomaterials.2004.04.035

8. Wu C, Wang W, Tian B, et al. Myricetin prevents titanium particle-induced osteolysis in vivo and inhibits rankl-induced osteoclastogenesis in vitro. Biochem Pharmacol. 2015;93(1):59-71. doi:10.1016/j.bcp.2014.10.019

9. Nich C, Takakubo Y, Pajarinen J, et al. Macrophages-key cells in the response to wear debris from joint replacements. J Biomed Mater Res A. 2013;101(10):3033-3045. doi:10.1002/jbm.a.34599
10. Drees P, Eckardt A, Gay RE, Gay S, Huber LC. Mechanisms of disease: molecular insights into aseptic loosening of orthopedic implants. Nat Clin Pract Rheumatol. 2007;3(3):165-171. doi:10.1038/ncprheum0428

11. Liu S, Liu D, Chen C, et al. MSC transplantation improves osteopenia via epigenetic regulation of Notch signaling in lupus. Cell Metab. 2015;22(4):606-618. doi:10.1016/j.cmet.2015.08.018

12. Lavasani M, Robinson AR, Lu A, et al. Muscle-derived stem/progenitor cell dysfunction limits healthspan and lifespan in a murine progeria model. Nat Commun. 2012;3:608. doi:10.1038/ncomms1611

13. Tkach M, Thery C. Communication by extracellular vesicles: where we are and where we need to go. Cell. 2016;164(6):1226-1232. doi:10.1016/j.cell.2016.01.043

14. Syn N, Wang L, Sethi G, Thiery JP, Goh BC. Exosome-mediated metastasis: from epithelial-mesenchymal transition to escape from immunosurveillance. Trends Pharmacol Sci. 2016;37(7):606-617. doi:10.1016/j.tips.2016.04.006

15. Hu Y, Xu R, Chen CY, et al. Extracellular vesicles from human umbilical cord blood ameliorate bone loss in senile osteoporotic mice. Metabolism. 2019;95:93-101. doi:10.1016/j. metabol.2019.01.009

16. Qi X, Zhang J, Yuan H, et al. Extracellular vesicles secreted by human-induced pluripotent stem cell-derived mesenchymal stem cells repair critical-sized bone defects through enhanced angiogenesis and osteogenesis in osteoporotic rats. Int J Mol Sci. 2016;12 (7):836-849.

17. Chen CY, Rao SS, Ren L, et al. Exosomal DMBT1 from human urine-derived stem cells facilitates diabetic wound repair by promoting angiogenesis. Theranostics. 2018;8(6):1607-1623. doi:10.7150/ thno. 22958

18. Liang G, Zhang Y. Genetic and epigenetic variations in iPSCs: potential causes and implications for application. Cell Stem Cell. 2013;13(2):149-159. doi:10.1016/j.stem.2013.07.001

19. Roubelakis MG, Pappa KI, Bitsika V, et al. Molecular and proteomic characterization of human mesenchymal stem cells derived from amniotic fluid: comparison to bone marrow mesenchymal stem cells. Stem Cells Dev. 2007;16(6):931-952. doi:10.1089/ scd.2007.0036

20. Zhang Y, McNeill E, Tian H, et al. Urine derived cells are a potential source for urological tissue reconstruction. J Urol. 2008;180 (5):2226-2233. doi:10.1016/j.juro.2008.07.023

21. Zhang D, Wei G, Li P, Zhou X, Zhang Y. Urine-derived stem cells: a novel and versatile progenitor source for cell-based therapy and regenerative medicine. Genes Dis. 2014;1(1):8-17. doi:10.1016/j. gendis.2014.07.001

22. Bodin A, Bharadwaj S, Wu S, Gatenholm P, Atala A, Zhang Y. Tissueengineered conduit using urine-derived stem cells seeded bacterial cellulose polymer in urinary reconstruction and diversion. Biomaterials. 2010;31(34):8889-8901. doi:10.1016/j. biomaterials.2010.07.108

23. Zhou T, Benda C, Dunzinger S, et al. Generation of human induced pluripotent stem cells from urine samples. Nat Protoc. 2012;7 (12):2080-2089. doi:10.1038/nprot.2012.115

24. Guan J, Zhang J, Li H, et al. Human urine derived stem cells in combination with beta-TCP can be applied for bone regeneration. PLoS One. 2015;10(5):e0125253. doi:10.1371/journal.pone.0125253

25. Green TR, Fisher J, Matthews JB, Stone MH, Ingham E. Effect of size and dose on bone resorption activity of macrophages by in vitro clinically relevant ultra high molecular weight polyethylene particles. $J$ Biomed Mater Res. 2000;53(5):490-497. doi:10.1002/1097-4636(200009)53:5<490::AID-JBM7>3.0.CO;2-7

26. Zaveri TD, Dolgova NV, Lewis JS, Hamaker K, Clare-Salzler MJ, Keselowsky BG. Macrophage integrins modulate response to ultrahigh molecular weight polyethylene particles and direct particle-induced osteolysis. Biomaterials. 2017;115:128-140. doi:10.1016/j.biomaterials.2016.10.038 
27. Chen W, Bichara DA, Suhardi J, Sheng P, Muratoglu OK. Effects of vitamin E-diffused highly cross-linked UHMWPE particles on inflammation, apoptosis and immune response against $\mathrm{S}$. aureus Biomaterials. $\quad 2017 ; 143: 46-56 . \quad$ doi:10.1016/j. biomaterials.2017.07.028

28. Wu C, Chen L, Huang YZ, et al. Comparison of the proliferation and differentiation potential of human urine-, placenta decidua basalisand bone marrow-derived stem cells. Stem Cells Int. 2018;2018:7131532. doi:10.1155/2018/7131532

29. Yim N, Ryu SW, Choi K, et al. Exosome engineering for efficient intracellular delivery of soluble proteins using optically reversible protein-protein interaction module. Nat Commun. 2016;7:12277. doi:10.1038/ncomms 12277

30. Costa-Verdera H, Gitz-Francois JJ, Schiffelers RM, Vader P. Cellular uptake of extracellular vesicles is mediated by clathrin-independent endocytosis and macropinocytosis. $J$ Control Release. 2017;266:100-108. doi:10.1016/j.jconrel.2017.09.019

31. Thery C, Amigorena S, Raposo G, Clayton A. Isolation and characterization of extracellular vesicles from cell culture supernatants and biological fluids. Curr Protoc Cell Biol. 2006;3(Unit 3):22.

32. Ormsby RT, Cantley M, Kogawa M, et al. Evidence that osteocyte perilacunar remodeling contributes to polyethylene wear particle induced osteolysis. Acta Biomater. 2016;33:242-251.

33. Chen L, Li L, Xing F, et al. Human urine-derived stem cells: potential for cell-based therapy of cartilage defects. Stem Cells Int. 2018;2018:4686259. doi:10.1155/2018/4686259

34. Bharadwaj S, Liu G, Shi Y, et al. Multipotential differentiation of human urine-derived stem cells: potential for therapeutic applications in urology. Stem Cells. 2013;31(9):1840-1856. doi:10.1002/ stem. 1424

35. Colombo M, Raposo G, Théry C. Biogenesis, secretion, and intercellular interactions of extracellular vesicles and other extracellular vesicles. Annu Rev Cell Dev Biol. 2014;30:255-289. doi:10.1146/ annurev-cellbio-101512-122326

36. Zawawi MS, Marino V, Perilli E, et al. Parthenolide reduces empty lacunae and osteoclastic bone surface resorption induced by polyethylene particles in a murine calvarial model of peri-implant osteolysis. J Biomed Mater Res A. 2015;103(11):3572-3579. doi:10.1002/jbm.a.35484

37. Nabeshima A, Pajarinen J, Lin TH, et al. Mutant CCL2 protein coating mitigates wear particle-induced bone loss in a murine continuous polyethylene infusion model. Biomaterials. 2017;117:1-9. doi:10.1016/j.biomaterials.2016.11.039

38. Delanois RE, Mistry JB, Gwam CU, Mohamed NS, Choksi US, Mont MA. Current epidemiology of revision total knee arthroplasty in the United States. $J$ Arthroplasty. 2017;32(9):2663-2668. doi:10.1016/j.arth.2017.03.066

39. Gwam CU, Mistry JB, Mohamed NS, et al. Current epidemiology of revision total hip arthroplasty in the United States: national inpatient sample 2009 to 2013. J Arthroplasty. 2017;32(7):2088-2092. doi:10.1016/j.arth.2017.02.046

40. Gao P, Han PL, Jiang DP, Yang SL, Cui QB, Li ZZ. Effects of the donor age on proliferation, senescence and osteogenic capacity of human urine-derived stem cells. Cytotechnology. 2017;69 (5):751-763. doi:10.1007/s10616-017-0084-5

41. Chen CY, Rao SS, Tan YJ, et al. Extracellular vesicles from human urine-derived stem cells prevent osteoporosis by transferring CTHRC1 and OPG. Bone Res. 2019;7:18. doi:10.1038/s41413-0190056-9
42. Guan J, Zhang J, Guo S, et al. Human urine-derived stem cells can be induced into osteogenic lineage by silicate bioceramics via activation of the Wnt/ $\beta$-catenin signaling pathway. Biomaterials. 2015;55:1-11. doi:10.1016/j.biomaterials.2015.03.029

43. $\mathrm{Xu} \mathrm{S}$, Liu C, Ji HL. Concise review: therapeutic potential of the mesenchymal stem cell derived secretome and extracellular vesicles for radiation-induced lung injury: progress and hypotheses. Stem Cells Transl Med. 2019;8(4):344-354. doi:10.1002/sctm.18-0038

44. Zheng G, Huang R, Qiu G, et al. Mesenchymal stromal cell-derived extracellular vesicles: regenerative and immunomodulatory effects and potential applications in sepsis. Cell Tissue Res. 2018;374 (1):1-15. doi:10.1007/s00441-018-2871-5

45. Lener T, Gimona M, Aigner L, et al. Applying extracellular vesicles based therapeutics in clinical trials - an ISEV position paper. J Extracell Vesicles. 2015;4:30087. doi:10.3402/jev.v4.30087

46. Zhang Y, Chopp M, Meng Y, et al. Effect of extracellular vesicles derived from multipluripotent mesenchymal stromal cells on functional recovery and neurovascular plasticity in rats after traumatic brain injury. $J$ Neurosurg. 2015;122(4):856-867. doi:10.3171/ 2014.11.JNS14770

47. Cuetara BL, Crotti TN, O’Donoghue AJ, McHugh KP. Cloning and characterization of osteoclast precursors from the RAW264.7 cell line. In Vitro Cell Dev Biol Anim. 2006;42(7):182-188. doi:10.1290/0510075.1

48. Li CJ, Cheng P, Liang MK, et al. MicroRNA-188 regulates agerelated switch between osteoblast and adipocyte differentiation. J Clin Invest. 2015;125(4):1509-1522. doi:10.1172/JCI77716

49. Xie H, Cui Z, Wang L, et al. PDGF-BB secreted by preosteoclasts induces angiogenesis during coupling with osteogenesis. Nat Med. 2014;20(11):1270-1278. doi:10.1038/nm.3668

50. Hu Y, Zhang Y, Ni CY, et al. Human umbilical cord mesenchymal stromal cells-derived extracellular vesicles exert potent bone protective effects by CLEC11A-mediated regulation of bone metabolism. Theranostics. 2020;10(5):2293-2308. doi:10.7150/thno.39238

51. Zhai MM, Zhu Y, Yang MY, Mao CB. Human mesenchymal stem cell derived exosomes enhance cell-free bone regeneration by altering their mirnas profiles. Adv Sci (Weinh). 2020;7(19):2001334. doi:10.1002/advs.202001334

52. Furuta T, Miyaki S, Ishitobi H, et al. Mesenchymal stem cell-derived exosomes promote fracture healing in a mouse model. Stem Cells Transl Med. 2016;5(12):1620-1630. doi:10.5966/sctm.2015-0285

53. Xu RY, Shen X, Si YM, et al. MicroRNA-31a-5p from aging BMSCs links bone formation and resorption in the aged bone marrow microenvironment. Aging Cell. 2018;17(4):e12794. doi:10.1111/ acel.12794

54. Xian PP, Hei Y, Wang R, et al. Mesenchymal stem cell-derived exosomes as a nanotherapeutic agent for amelioration of inflammation-induced astrocyte alterations in mice. Theranostics. 2019;9(20):5956-5975. doi:10.7150/thno.33872

55. Li JY, Niu CC, Jiang ZC, et al. Targeted delivery of curcumin to polyethylene-induced osteolysis by magnetically guided zoledronateanchored poly lactic-co-glycolic acid nanoparticles via repressing NF-кB signaling. Front Pharmacol. 2020;11:600156. doi:10.3389/ fphar.2020.600156

56. Hu XY, Ping Z, Gan MF, et al. Theaflavin-3,3'-digallate represses osteoclastogenesis and prevents wear debris-induced osteolysis via suppression of ERK pathway. Acta Biomaterialia. 2016;48:479-488. doi:10.1016/j.actbio.2016.11.022 


\section{Publish your work in this journal}

The International Journal of Nanomedicine is an international, peerreviewed journal focusing on the application of nanotechnology in diagnostics, therapeutics, and drug delivery systems throughout the biomedical field. This journal is indexed on PubMed Central, MedLine, CAS, SciSearch ${ }^{\mathbb{R}}$, Current Contents ${ }^{\mathbb{B}} /$ Clinical Medicine,
Journal Citation Reports/Science Edition, EMBase, Scopus and the Elsevier Bibliographic databases. The manuscript management system is completely online and includes a very quick and fair peer-review system, which is all easy to use. Visit http://www.dovepress.com/ testimonials.php to read real quotes from published authors. 